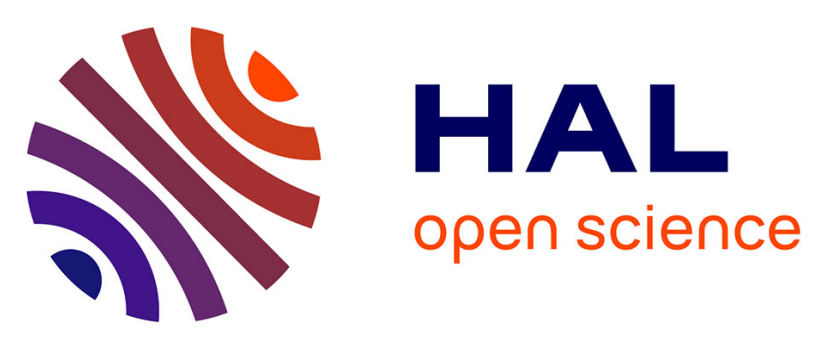

\title{
Combining XANES, ICP-AES, and SEM/EDS for the study of phytate chelating treatments used on iron gall ink damaged manuscripts
}

\author{
Véronique Rouchon, Eleonora Pellizzi, Maroussia Duranton, Frederik \\ Vanmeert, Koen Janssens
}

\section{To cite this version:}

Véronique Rouchon, Eleonora Pellizzi, Maroussia Duranton, Frederik Vanmeert, Koen Janssens. Combining XANES, ICP-AES, and SEM/EDS for the study of phytate chelating treatments used on iron gall ink damaged manuscripts. Journal of Analytical Atomic Spectrometry, 2011, 10.1039/c1ja10185d . hal-01447280

\author{
HAL Id: hal-01447280 \\ https://hal.science/hal-01447280
}

Submitted on 26 Jan 2017

HAL is a multi-disciplinary open access archive for the deposit and dissemination of scientific research documents, whether they are published or not. The documents may come from teaching and research institutions in France or abroad, or from public or private research centers.
L'archive ouverte pluridisciplinaire HAL, est destinée au dépôt et à la diffusion de documents scientifiques de niveau recherche, publiés ou non, émanant des établissements d'enseignement et de recherche français ou étrangers, des laboratoires publics ou privés. 


\title{
Combining XANES, ICP-AES, and SEM/EDS for the study of phytate chelating treatments used on iron gall ink damaged manuscripts
}

\author{
Véronique Rouchon, ${ }^{* a}$ Eleonora Pellizzi, ${ }^{a}$ Maroussia Duranton, ${ }^{a}$ Frederik Vanmeert ${ }^{b}$ and Koen Janssens ${ }^{b}$
}

Received 24th June 2011, Accepted 1st September 2011

DOI: $10.1039 / c 1 j a 10185 d$

\begin{abstract}
Many historical documents written with iron gall inks are endangered by the corrosive effects of these inks. In this work, a combination of complementary analytical methods was used for the first time in order to study the "phytate" process which is used in conservation studios to stabilize damaged manuscripts. This process consists of an antioxidant treatment performed by means of a calcium phytate (CP) solution, followed by a deacidification treatment performed with a calcium carbonate (CC) solution. The antioxidant treatment capitalizes on the properties of myo-inositol hexaphosphoric acid (phytic acid) that inhibits iron through chelation. In order to use relatively low acidic solutions, the $\mathrm{pH}$ of the $\mathrm{CP}$ solution is increased up to values between 5 and 6 , which is in the range of the CP precipitation threshold. This study was performed on laboratory samples made of paper impregnated with iron gall ink and artificially aged in climatic chambers. It aims to investigate how the CP precipitate impacts the efficiency of the treatment. Side effects, such as elemental losses and deposits, were measured by means of several analytical techniques (Fe-K Edge XANES, SEM/EDS, and ICPAES). These measurements were crosschecked with a ready to use colour spot test made of bathophenanthroline impregnated paper. It appeared that the CP treatment should necessarily be followed by the deacidification treatment in order to achieve long term stability. The precipitation of $\mathrm{CP}$ in the treating solution does finally not impact the efficiency of the treatment despite the fact that it should theoretically lower the availability of phytate to chelate iron. A scenario is proposed to explain this point.
\end{abstract}

\section{Introduction}

Iron gall inks (IGI) have been extensively used in Western and Middle Eastern countries for writing, and to a lesser extent for drawing. These inks are composed of Fe(II) sulphate, gall nuts, and gum arabic. The mixture of $\mathrm{Fe}(\mathrm{II})$ sulphate and gall nut aqueous extracts, rich in polyphenolic acids, turns instantly toward a dark colour, characteristic of an Fe(III) precipitate. The gum arabic is added to create a suspension of the particles of the precipitate and make the ink more suitable for writing. The chemistry of the iron gall ink/paper system is rather complex, mainly because of the high reactivity of iron that allows many interactions with surrounding components: complexation and/or precipitation with tannins, ${ }^{1-4}$ chelation with polysaccharides, ${ }^{5}$ redox reactions with polyphenolic acids such as gallic acid, ${ }^{6}$

${ }^{a}$ Centre de Recherche sur la Conservation des Collections, Muséum national d'histoire naturelle, Centre national de la recherche scientifique, Ministère de la Culture et de la Communication, USR3224, CP21, 36 rue Geoffroy-Saint-Hilaire, 75005 Paris, France. E-mail: rouchon@, mnhn.fr; Fax: +3314079 5312; Tel: +3314079 5303

${ }^{b}$ Department of Chemistry, University of Antwerp, Universiteitsplein 1, B2610 Antwerp, Belgium. E-mail: koen.janssens@ua.ac.be; Fax: +32 3265 2376; Tel: +3232652373 oxidation induced by atmospheric oxygen, etc. All these reactions may compete with each other.

Under certain conditions, IGI can cause a significant degradation of the paper. ${ }^{7,8}$ Two main mechanisms are proposed to explain this decline: the first is the hydrolysis of cellulose promoted by the acidity of the ink. The second corresponds to an oxidation of cellulose provoked by surrounding oxygen and enhanced by Fenton mechanisms. These notoriously complex reactions are exacerbated by $\mathrm{Fe}$ (II) (present in inks) and involve oxygen reactive species, such as peroxides. They lead to the formation of hydroxyl radicals ${ }^{9}$ and these highly reactive species provoke an oxidation of cellulose. It was demonstrated, although the detailed mechanism is not established, that the oxidized cellulose reorganizes through chain scissions. The predominance of oxidative mechanisms on cellulose depolymerization was first highlighted on deacidified IGI impregnated papers ${ }^{10}(\mathrm{pH} 6.5$ to 8 ). More recently, ${ }^{11}$ oxygen has been identified as a key factor for chain scissions occurring in IGI impregnated papers (whose $\mathrm{pH}$ was between 3 and 4), proving that paper degradation induced by IGI is mainly related to oxidative mechanisms.

A significant amount of work has been done in the last few years to document aqueous treatment side effects ${ }^{\mathbf{1 2}}$ and to investigate possible treatments to prevent the degradation of IGI 
manuscripts. ${ }^{13-17}$ Among the investigated possibilities, the calcium phytate treatment remains the most tested method. ${ }^{18-25}$ Although not (yet) extensively used, it is being employed on an experimental basis in several conservation studios, such as the National Archives of the Netherlands.

The phytate treatment capitalizes on the anti-oxidant properties of myo-inositol hexaphosphoric acid (phytic acid). ${ }^{26}$ Phytic acid is extensively studied because of its numerous applications in biology, medicine, and corrosion science. ${ }^{27}$ It is a strong chelator that can complex or precipitate with many polyvalent cations, such as $\mathrm{Ca}^{2+}, \mathrm{Fe}^{2+}$, or $\mathrm{Fe}^{3+}$. Mono-, di-, tri- and tetraferric phytate can be encountered, depending on the phytate/iron ratio present in solution. The solubility of phytate usually decreases with the number of cations bound to it. In the case of iron for instance, monoferric-phytate is highly soluble, whereas tetraferric phytate is highly insoluble. In contrast to many other chelators, phytate has the particularity to make iron unreactive. This point was experimentally evidenced at $\mathrm{pH} 7.4$ by Graf et al. ${ }^{27,28}$ The total inhibition of iron through phytate chelation is attributed to the fact that phytate is a chelator capable of occupying all coordination sites of iron, and thus prevents it to take part in Fenton reactions.

The treatment consists in immersing the manuscripts in phytic acid solutions in order to inhibit iron by chelation. However, this solution is not prepared with phytic acid only, because its $\mathrm{pH}$ would be too low for an appropriate application on valuable objects. The treatment procedure ${ }^{29}$ recommends to prepare a calcium phytate $(\mathrm{CP})$ solution and to raise its $\mathrm{pH}$ from its initial value of 2.9 up to a value between 5.5 and 6 . After the calcium phytate bath, the documents should be deacidified with a solution of calcium carbonate (CC) in order to reach a final $\mathrm{pH}$ close to 8 . The reason for not employing higher $\mathrm{pH}$ values for the $\mathrm{CP}$ solution is the limited solubility of $\mathrm{CP}$ that decreases with increasing $\mathrm{pH}$. Above a $\mathrm{pH}$ value of 5 , a white precipitate appears. Paper conservators do not feel very comfortable in immersing an original document in a white cloudy solution, because the CP precipitate might be retained on the paper surface, leading to unesthetical deposits. ${ }^{23,30}$ Moreover, the precipitation of CP may jeopardize the efficiency of the solution: if phytate precipitates with calcium, it theoretically should not be available for the inhibition of iron. Although the phytate treatment appears to have been extensively studied, its efficiency remains poorly understood. In particular, the behaviour of iron during the treatment remains unknown: is it largely removed from the paper because of its high affinity with solubilized phytate? Does it on the contrary precipitate with phytate at the surface of the paper? Does it get oxidized during the treatment? If oxidation is the driving force of chain scissions, ${ }^{11}$ why is it necessary to deacidify the paper after the anti-oxidant treatment?

In view of the above questions, this work was undertaken to understand the treatment. In particular it was investigated how the $\mathrm{pH}$ of $\mathrm{CP}$ solutions impacts the treatment efficiency. A specific methodology was defined for this purpose, combining several analytical tools: ICP-AES and UV fluorescence nitrogen analysis for absolute elemental concentrations, X-ray absorption near edge spectroscopy for the determination of iron oxidation state, and scanning electron microscopy coupled with an elemental detection system (SEM/EDS) for the evaluation of elemental deposit distribution.

\section{Experimental}

\section{Sample preparation}

Samples consisted of paper sheets impregnated with a diluted iron gall ink. Pure laboratory products were used for the preparation of the ink: monohydrate gallic acid (Aldrich, 398225), $0.6 \mathrm{~g} \mathrm{~L} \mathrm{~L}^{-1}$; heptahydrate $\mathrm{Fe}$ (II) sulphate (Aldrich, 215422), $2.66 \mathrm{~g} \mathrm{~L}^{-1}$; and gum arabic (Aldrich, G9752), $6 \mathrm{~g} \mathrm{~L}^{-1}$. The ink was stirred in a closed vessel for 3 days before use until it reaches a $\mathrm{pH}$ of $3.0 \pm 0.1$. The paper sheets (Whatman no. $1,85 \mathrm{~g} \mathrm{~m}^{-2}$, $10 \times 13 \mathrm{~cm}$ ) were immersed for 10 minutes in the ink solution, respecting a maximum ratio of $4 \mathrm{~cm}^{2}$ of paper per $1 \mathrm{~mL}$ of ink. After immersion, the sheets were placed between two Cobb blotting papers ${ }^{31}$ and the excess of ink was mopped up by using a $10 \mathrm{~kg}$ Cobb roll (one way pass and return). This procedure allows an even deposition of the ink, with a lateral dispersion of $\pm 5 \%$. The iron content deposited in the paper $\left(11 \mu \mathrm{Mol} \mathrm{g} \mathrm{g}^{-1}\right)$ remains inferior but close to the iron content of original manuscripts, which is usually over $20 \mu \mathrm{Mol} \mathrm{g}^{-1}$.2,33

As the paper is not charged nor sized, the ink is absorbed into the core of the paper, leading to a homogeneous distribution of iron, which is obviously not the case of original manuscripts. However, as argued elswhere, ${ }^{11}$ these samples are satisfactory models to simulate the chemistry of iron gall ink corrosion occurring in the paper. Moreover, their homogeneity enabled a relatively precise monitoring of the elemental losses and the oxidation state of iron, which is almost impossible on heterogeneous original samples. It additionally allowed us to measure the loss of physical properties by mechanical testing.

\section{Artificial ageing}

Samples were artificially aged in a Vötsch climatic chamber, using mild ageing conditions, namely $70{ }^{\circ} \mathrm{C}$ and $65 \% \mathrm{RH}$. Before treatment, the samples were aged for approximately 6 days in order to simulate some degradation of the paper and to achieve a decay of approx. $10-15 \%$ of mechanical properties. After treatment, the samples were aged again in the same conditions for approx. 2 months.

\section{The bathophenanthroline paper test (BPT)}

The $\mathrm{BPT}^{34}$ (Preservation Equipment, Iron Gall Ink Test Paper, 539-3000) was specifically formulated for paper conservation purposes. It consists of bathophenanthroline impregnated paper strips that turn red when exposed to Fe(II) containing solutions. This spot test is commonly applied by paper conservators in different ways. It is for instance advised ${ }^{35}$ for directly monitoring the efficiency of a curative treatment on the treated documents. ${ }^{36}$

\section{Implementation of the treatment}

$\mathrm{CP}$ solutions were prepared in the following way: ${ }^{28} 0.44 \mathrm{~g}$ of calcium carbonate (Prolabo, 22.3003290, Normapur, 99.5\%) was mixed with $2.3 \mathrm{~g}$ of phytic acid, 50\% w/w (Sigma Aldrich, 593648), until a brown unctuous paste was obtained, then diluted with $1 \mathrm{~L}$ of water. The $\mathrm{pH}$ of the $\mathrm{CP}$ solution was then monitored by addition of ammonia. In order to study the effect of the $\mathrm{CP}$ precipitation, four different values of $\mathrm{pH}$ were chosen: 
4.8 (transparent solution), 5.2 (turbid solution), 5.5 (white cloudy solution), and 6 (precipitate formation at the bottom of the container).

The CC solutions were prepared with a method close to that used in conservation workshops: $1.1 \mathrm{~g}$ of CC was added to $1 \mathrm{~L}$ of commercially available sparkling water (Perrier, $\mathrm{pH}$ 5.2, composition in $\mathrm{mg} \mathrm{L}^{-1}: \mathrm{Ca}^{2+}, 155 ; \mathrm{Mg}^{2+}, 7 ; \mathrm{Na}^{+}, 12 ; \mathrm{SO}_{4}{ }^{2-}, 46$; $\mathrm{Cl}^{-}, 25$; and $\left.\mathrm{HCO}_{3}^{-}, 445\right)$. The use of sparkling water is motivated by the fact that (a) it dissolves easily a reproducible amount of calcium carbonate $\left(0.8 \mathrm{~g} \mathrm{~L}^{-1}\right)$, (b) the sulphate and chloride content of the sparkling water had no significant impact on the paper composition after treatment (unpublished results). The bottles were closed immediately after addition, then left to rest for 24 hours before use. Only the supernatant was used ( $\mathrm{pH} 5.8 \pm$ $0.2)$.

The various treatments that were implemented are listed in Table 1. Each immersion was performed using $2 \mathrm{~mL}$ of solution per $1 \mathrm{~cm}^{2}$ of paper. The presence of free $\mathrm{Fe}(\mathrm{II})$ was checked with the BPT on each phytate solution after 15 minutes of sample immersion. For all CP solutions, the test was positive, suggesting that all the phytate was consumed, and that it was necessary to pursue the treatment. At the end of a second bath of 15 minutes, the BPT remained negative, meaning that the $\mathrm{CP}$ immersion could be stopped and completed if necessary via the $\mathrm{CC}$ deacidification. For a better homogeneity of the procedures, this last treatment was also performed by means of a sequence of two baths, of 15 minutes each.

\section{Evaluation of the treatment efficiency}

As conservation treatments in the first place aim to limit physical decay to the paper, mechanical testing appeared meaningful for the evaluation of treatment efficiency. The paper mechanical properties were evaluated with a Zero-span tensile tester ${ }^{37}$ (Pulmac, TS-100) on dried papers, pre-conditioned at $23{ }^{\circ} \mathrm{C}$ and $50 \% \mathrm{RH}$. This test consists in measuring the failure load necessary to break a strip of paper maintained by adjacent jaws. The load is expressed in $\mathrm{kg}$ per $15 \mathrm{~mm}$ of strip width. For each sample, 10 measurements were performed and the average was considered. Standard deviations were ranging from $2 \%$ to $6 \%$.

Mechanical testing was completed with $\mathrm{pH}$ measurements performed on cold extracts, prepared with $0.5 \mathrm{~g}$ of paper in $25 \mathrm{~mL}$ of decarbonated ultrapure water. ${ }^{38}$

Table 1 List of implemented treatments

\begin{tabular}{llll}
\hline Name & Distilled water & CP solution & CC solution \\
\hline W30 & 2 baths & - & - \\
W60 & 4 baths & - & - \\
Phy-1 & - & 2 baths (pH 4.8) & - \\
Phy-2 & - & 2 baths (pH 5.2) & - \\
Phy-3 & - & 2 baths (pH 5.5) & - \\
Phy-4 & - & 2 baths (pH 6) & - \\
Bi & - & 2 baths (pH 4.8) & 2 baths \\
PhyBi-1 & - & 2 baths (pH 5.2) & 2 baths \\
PhyBi-2 & - & 2 baths (pH 5.5) & 2 baths \\
PhyBi-3 & - & 2 baths (pH 6) & 2 baths \\
PhyBi-4 & - & &
\end{tabular}

\section{Elemental analysis}

The sulfur content was measured with a UV fluorescence nitrogen analyser (TN/TS 3000, Thermofisher Scientific), after the total combustion of approx. $5 \mathrm{mg}$ of samples at $1000^{\circ} \mathrm{C}$ in the presence of argon and oxygen (in order to assure the conversion of sulfur into sulfur dioxide). All samples were triplicated and the average was considered. The concentrations in iron, calcium and phosphorus were measured by ICP-AES (ICAP 6300, Thermofisher Scientific), after the mineralization of approx. $30 \mathrm{mg}$ of samples in $25-100 \mathrm{~mL}$ of concentrated nitric acid according to a standard procedure. ${ }^{39}$ Standard solutions were used for the calibration, and additionally during the analysis to check the stability of the apparatus.

Topological information on the compounds that are deposited on the paper after treatment were collected by Scanning Electron Microscopy (JEOL 5410 LV), equipped with an EDS probe (Oxford, Link Pentafet) that allows elemental mapping (Experimental conditions: $20 \mathrm{keV}$ beam, diaphragm 2, $20 \mathrm{~Pa}$ low vacuum, no sample preparation). An acquisition time of one or two hours was sufficient to achieve a satisfactory statistic (over 100 counts).

All maps were recorded at low magnification $(\times 35$ to $\times 50)$ on a region that includes both treated and untreated areas in order to allow a qualitative comparison of elemental distribution. All samples were duplicated or triplicated in different areas of the same paper sheet in order to assure the reliability of the observations.

In order to evaluate if elemental deposits are distributed on the paper surface only, or in the paper core, some of the treated paper were split into two parts, parallel to their surface. The inner part of the sheet was then accessible for SEM observation.

\section{Determination of iron oxidation via Fe-K Edge XANES}

XANES spectra were recorded in the energy range from 7060 to $7260 \mathrm{eV}$, employing 200 data points with a spacing of $1 \mathrm{eV}$ and a dwell time of 1 or $2 \mathrm{~s}$ per point. The DIFFABS beamline of the SOLEIL synchrotron (Saint Aubin, France) was appropriate for this type of experiment because the beam could easily be defocused to approx. $300 \times 800$ micron large. The sample was tilted to $45^{\circ}$ with respect to the incident beam, resulting in a global analysed area of approximately $1100 \times 400$ micron large. This geometry was found necessary to (a) avoid iron photo-reduction phenomena ${ }^{40}$ and (b) average the signal on a macroscopic scale, thus achieving reproducible measurements. All recorded Fe-XANES profiles from ink + paper samples with unknown $\mathrm{Fe}$ (II)/Fe(III) content could satisfactorily be expressed as a linear combination of the XANES profiles derived from the reference compounds heptahydrate Fe(II)-sulphate (Aldrich, 215422) and pentahydrate $\mathrm{Fe}(\mathrm{III})$-sulphate $\left(\mathrm{Fe}_{2}\left(\mathrm{SO}_{4}\right)_{3} \cdot 5 \mathrm{H}_{2} \mathrm{O}, \quad\right.$ Aldrich, 30 771-8) (see Fig. 1). The satisfactory description of XANES spectra by only the above-mentioned two reference spectra is probably due to the fact that (a) most of the iron that is present in untreated samples is bound to the (abundantly present) sulphate ions, (b) most of the $\mathrm{Fe}(\mathrm{III})$ that is present in phytate treated samples is bound to phosphate ions, (c) the XANES spectra of $\mathrm{Fe}$ (III) sulphate/oxohydroxides are very close to that of $\mathrm{Fe}$ (III) phosphate ${ }^{41,42}$ and (d) the shape of the XANES spectra is mainly 


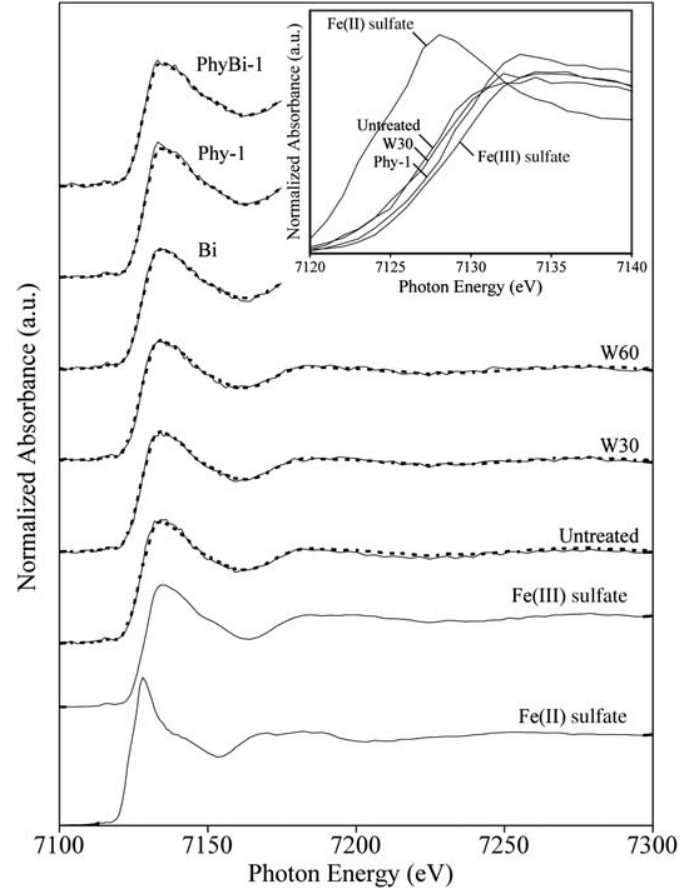

Fig. 1 Xanes spectra - experimental data (grey lines) and fit (dashed lines).

related to the oxidation state of iron and only to a lesser degree depends on its speciation.

The linear combination of reference spectra allows to determine $\mathrm{Fe}(\mathrm{II}) / \mathrm{Fe}(\mathrm{III})$ ratios situated in the range $10 \% / 90 \%$ to $90 \%$ / $10 \%$ with an uncertainty of $c a . \pm 5 \%$ absolute, the latter value deriving mainly from the uncertainty on the regression coefficients.

\section{Results}

\section{Identification of the most efficient treatments}

Fig. 2 shows that the untreated samples are the most damaged. After 3 months of artificial ageing, they have lost $80 \%$ of their zero span breaking load. In comparison, the samples that were washed in water only (W30 and W60) are less damaged: the

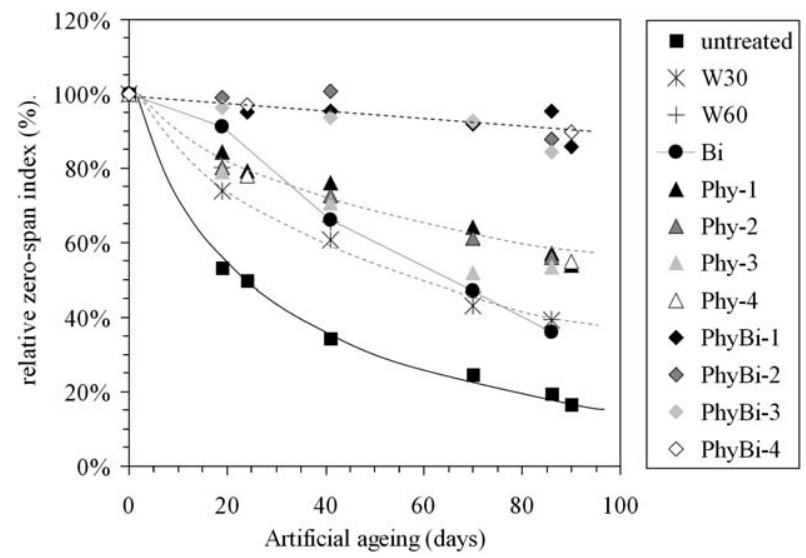

Fig. 2 Mechanical decay of treated samples versus artificial ageing. removal of soluble compounds delays the paper degradation, however, without stopping it. The benefit of CP solutions is similar for all investigated $\mathrm{pH}$ values (Phy-1 to Phy-4) and slightly higher than that of water washing, but these treatments remain of limited efficiency. The $\mathrm{CC}$ treatment, when used by itself (Bi), gives rise to a short term beneficial effect only.

In contrast to all the above, excellent results were obtained using a combination of $\mathrm{CP}$ and $\mathrm{CC}$ (PhyBi-1 to PhyBi-4): after 3 months of artificial ageing, only a $10 \%$ loss of zero span breaking load is observed, irrespective of the $\mathrm{pH}$ of the $\mathrm{CP}$ solution that was employed.

\section{Evolution of the $\mathrm{pH}$}

The evolution of the $\mathrm{pH}$ as a function of artificial ageing time is plotted in Fig. 3. The $\mathrm{pH}$ of untreated samples remains very stable during the degradation. The acidity brought by the ink remains in the paper and the ongoing damaging reactions do not render the paper more acidic to a perceptible level.

The washing effect of water observed in Fig. 2 is noticeable again in Fig. 3: the removal of soluble compounds from the samples increases the $\mathrm{pH}$ by approx. 1 unit, meaning that some of the washed out compounds are acids. But contrary to untreated samples, the $\mathrm{pH}$ of washed samples decreases during artificial ageing and finally recovers its initial value.

The deacidification realized by means of the $\mathrm{CC}$ solution raises the $\mathrm{pH}$ up to alkaline values (close to 8). However, when deacidification is performed employing only bicarbonate (Bi), this effect does not last very long and the $\mathrm{pH}$ falls back to a level of approx. 5 during the first month of artificial ageing. This decline is limited when the samples are treated with CP prior to deacidification (PhyBi-1 to PhyBi-4): in these cases, the $\mathrm{pH}$ stabilizes around a value of 6 after one month of artificial ageing.

\section{Iron and sulfur losses}

Whatman paper is both a porous and absorbent material. Consequently, when it is impregnated with pure water in a way similar to the inking process of our laboratory samples, it can retain water to a ratio of $115 \%$ of its own weight. Considering that the ink is diluted and thus presents a viscosity close to that of pure water, one may estimate that the amount of iron deposited

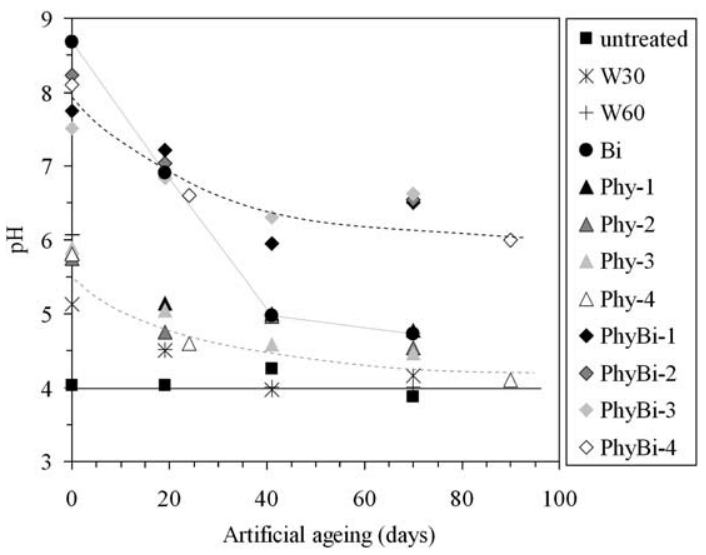

Fig. 3 Evolution of $\mathrm{pH}$ versus artificial ageing. 
by the ink is close to $11 \mu \mathrm{Mol} \mathrm{g}^{-1}$. This value is similar to the measurement performed on untreated papers (see Table 2), meaning that there is no preferential absorption of iron. Moreover, on these samples, the molar contents of iron and sulfur are similar, suggesting that a great part of iron is deposited as iron sulphate. Only a minor fraction of iron is likely to be precipitated with gallic acid, as attested by the light blue colour of the papers. This predominance of iron sulphates over the iron/gallic acid precipitate is not astonishing as it was already observed on ink samples. ${ }^{43}$

During aqueous treatments, iron and sulfur behave differently: sulfur, present in the sulphate form, is entirely dissolved, whatever the other species present in the treating solution, whereas iron mostly remains in the paper, in different quantities depending on the solution considered. Oxidized cellulose, because of its hydroxyl, aldehyde and carboxylic groups, has probably more affinity towards cations than anions, and thus retains iron while sulphate is easily dissolved. As iron presents six coordination sites, it may possibly be bonded at the same time with cellulose and sulphate. During immersion, all sulphates are dissolved, but a major part of the iron remains bound to the paper.

Pure water appears to be the most efficient for iron removal. After one hour, a loss of $50 \%$ of the initial amount of iron is observed.

This value is very close to the loss of $40 \%$ measured after 30 minutes, showing that most of the solubilisation process takes place during the first 30 minutes of immersion. Iron is more likely to remain in the paper when $\mathrm{CP}$ or $\mathrm{CC}$ is present in solution. In this case, only $30 \%$ of iron is lost. This ratio increases slightly up to $40-45 \%$ when the solution used is at $\mathrm{pH} 6$ (Phy-4 and PhyBi-4). It is then close to the value obtained with pure water (W30 and W60). This may be due to the fact that, at $\mathrm{pH} 6$, the greater part of $\mathrm{CP}$ is precipitated and the concentration of dissolved CP is very low.

In our experimental procedures, the phytate concentration in the solution is $1.75 \mathrm{mM}$, and the concentration of iron in solution remains below $0.044 \mathrm{mM}$, a value estimated under the assumption that all iron present in the paper is dissolved. Phytate is also present in large excess compared to iron. In these conditions, its high affinity toward iron is expected to lead to

Table 2 Elemental composition of paper samples in micro $\mathrm{Mol} \mathrm{g}^{-1}$

\begin{tabular}{lllll}
\hline Name & $\mathrm{S}$ & $\mathrm{Fe}$ & $\mathrm{Ca}$ & $\mathrm{P}$ \\
\hline Virgin paper $^{a}$ & 0.5 & 0.09 & 5 & - \\
Inked and untreated & $9.5(9)$ & $11.1(11)$ & $1.3(3)$ & $<0.2$ \\
W30 & $<0.3$ & $6.6(6)$ & $1.4(3)$ & $<0.2$ \\
W60 & $<0.3$ & $5.5(6)$ & $1.2(3)$ & $<0.2$ \\
Phy-1 & $<0.3$ & $7.9(8)$ & $19(2)$ & $32(3)$ \\
Phy-2 & $<0.3$ & $8.0(8)$ & $22(2)$ & $37(4)$ \\
Phy-3 & $<0.3$ & $7.9(8)$ & $24(3)$ & $40(4)$ \\
Phy-4 & $<0.3$ & $6.1(6)$ & $14(2)$ & $24(2)$ \\
Bi & $<0.3$ & $7.9(8)$ & $30(3)$ & $<0.2$ \\
PhyBi-1 & $<0.3$ & $7.8(8)$ & $43(5)$ & $23(2)$ \\
PhyBi-2 & $<0.3$ & $8.4(8)$ & $43(5)$ & $20(2)$ \\
PhyBi-3 & $<0.3$ & $8.4(8)$ & $43(5)$ & $23(2)$ \\
PhyBi-4 & $<0.3$ & $7.0(7)$ & $35(4)$ & $13(1)$ \\
a Data provided by the supplier. & & & \\
\hline
\end{tabular}

the formation of soluble iron phytate $1: 1$ complexes, thus facilitating iron removal from the paper in comparison to pure water. This is not the case. Far from enhancing iron removal from the samples, the $\mathrm{CP}$ solution helps to retain iron in the paper. This behaviour is related to the influence of calcium: the addition of calcium in iron phytate solutions is known to provoke co-precipitation phenomena. ${ }^{44}$ Non-stoichiometric coprecipitates are likely to be formed because the potential of twelve-coordinate ligands in the phytate molecule enables a large number of chelation possibilities. In the case of polyvalent ions, such as calcium or iron, chelation may occur via intra- and inter-molecular bonds, resulting in polymeric species of elevated molecular weights which render them insoluble. In our case, calcium is used at a concentration of $4.4 \mathrm{mM}$, i.e. in large excess over iron. Iron is also probably incorporated into the calcium:phytate precipitate without changing the Ca:Phy stoichiometry to a perceptible level.

\section{Calcium and phosphorus deposits}

Some of the treating solution remains in the paper when it is removed from the bath. This remaining solution (approx. 270\% of the initial paper weight) induces, after drying, elemental deposits, estimated to approx. 29 micro Mol of phosphorus per gram of paper, which is a value very close to what is measured for the treatment Phy-1. Table 2 shows that the amount of deposited phosphorus increases with the $\mathrm{pH}$ of the treating solution up to 40 micro $\mathrm{Mol} \mathrm{g}^{-1}$ at $\mathrm{pH} 5.5$ (Phy-3), attesting that a precipitation of $\mathrm{CP}$ is occurring during the immersion. Phosphorus deposit suddenly decreases down to 24 micro $\mathrm{Mol} \mathrm{g}^{-1}$ at $\mathrm{pH} 6$ (Phy-4), probably because there is less $\mathrm{CP}$ available in solution at this $\mathrm{pH}$ value.

Regarding calcium, the remaining solution of phytate is expected to deposit approx. 12 micro Mol of calcium per gram of paper. This value is approx. half of what is measured in Table 2 for the Phy-1 to Phy-3 treatments, showing a strong interaction between calcium and cellulose during the immersion. This point is confirmed on calcium bicarbonate $(\mathrm{Bi})$ treated samples: the measured calcium deposit (Bi sample, 30 micro $\mathrm{Mol} \mathrm{g}^{-1}$, Table 2) is largely superior to the value that could be estimated solely considering the remaining solution of $\mathrm{CC}$ in the paper (22 micro

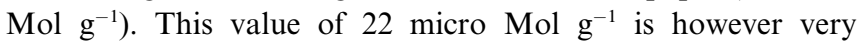
comparable to the increase of calcium obtained on PhyBi samples during deacidification, probably because the calciumcellulose interaction is lowered by the already present CP deposit.

The strong interaction between calcium and altered cellulose may possibly explain the short term efficiency of the Bi treatment, but needs further investigation to be well understood. The calcium deposited by the $\mathrm{CC}$ solution (Bi) corresponds to a small alkaline reserve of $0.3 \% \mathrm{w} / \mathrm{w} \mathrm{CaCO}_{3}$ (ref. 45) (see Table 2: Ca: 30 micro $\mathrm{Mol} \mathrm{g}^{-1}$ ). This low amount is due to the poor solubility of $\mathrm{CC}$ but is enough to render the paper alkaline $(\mathrm{pH} \mathrm{8)}$ after treatment. SEM imaging performed on Bi samples shows that calcium is deposited evenly throughout the paper sheet in concentration slightly above the detection limit of the SEM apparatus. Additionally, small particles rich in calcium and approx. 2 to 20 micrometres in size are observed on the paper surface, but are absent in the inner part of the sheet. As these particles do not contain any sulfur, they probably consist of $\mathrm{CC}$, 
already present in the CC solutions and deposited on the paper surface during immersion.

When CP solutions are used (samples Phy-1 to Phy-4), the areas on which calcium is deposited coincide with those of phosphorus, meaning that $\mathrm{CP}$ solutions mainly deposit $\mathrm{CP}$ in the paper sheet. Below the precipitation threshold (sample Phy-1), $\mathrm{CP}$ is deposited evenly on the paper fibers in a quantity close to the detection limit of the apparatus. Above pH 5 (samples Phy-2 to Phy-4), this even deposition is superimposed with aggregates of $\mathrm{CP}$ observed on the paper surface. The observation of several samples of the same kind suggests that these aggregates are more numerous at $\mathrm{pH} 5.5$ than at other $\mathrm{pH}$ values. As these aggregates are absent from the inner part of the sheet, they probably correspond to $\mathrm{CP}$ precipitates, already formed in the treatment solution, that are deposited during immersion.

The calcium and phosphorus contents of the Phy-1 samples (see Table 2) are somehow lower, but relatively similar to those of the Phy-3 samples on which the most abundant CP aggregates were noticed. This means that the deposited $\mathrm{CP}$ aggregates observed on the paper surface by SEM/EDX only correspond to a minor fraction of the total CP deposited in the sample. Also, during the phytate treatment most of the CP that remains in the paper is deposited homogeneously in the paper.

The molar $\mathrm{Ca} / \mathrm{P}$ ratios of the samples Phy-1 to Phy-4 (see Table 2) are similar $(0.605 \pm 0.05)$, whereas the total concentration of deposits varies significantly from one sample to another (Ca: 14 to 24 micro $\mathrm{Mol} \mathrm{g}^{-1}$; P: 24 to 40 micro $\mathrm{Mol} \mathrm{g}^{-1}$ ). In the $\mathrm{pH}$ range $4.8-6$, the $\mathrm{CP}$ is deposited in the samples with an average stoichiometry of 3.6 calcium atoms per phytate molecule. This stoichiometry is consistent with existing data: the Ca : phytate $n: 1$ is known to be soluble for low values of $n(n=1$ and $n=2)$, and insoluble for higher $n$ values $(2<n) \cdot{ }^{46} \mathrm{~A}$ stoichiometry of 3.6 suggests that the precipitate is a mixture of $\mathrm{Ca}:$ phytate $3: 1, \mathrm{Ca}:$ phytate $3.5: 1$ and $\mathrm{Ca}:$ phytate $4: 1$. The speciation of phytate solutions can be calculated versus $\mathrm{pH}$ considering the twelve $\mathrm{p} K_{\mathrm{a}}$ values of this acid: ${ }^{47}$ in the $\mathrm{pH}$ range 5 to 6 , to remove three species of phytate, respectively bound to 4 , 5 and 6 protons are co-existing in solution, meaning that respectively 8,7 , and 6 free sites remain available for calcium bounding. If we consider that each calcium can occupy maximum two available phytate sites, and that calcium does not remove bound protons, the resulting $\mathrm{Ca}$ : phytate precipitate stoichiometry should be between $3: 1$ and $4: 1$, consistent with the measured value of $3.6: 1$. It should additionally be noticed that this stoichiometry of $3.6: 1$ is significantly different from the initial stoichiometry of the solution $(2.5: 1)$ and slightly inferior to the maximum "ideal" stoichiometry of $4: 1$ found by Mali et al. ${ }^{42}$ on iron:phytate precipitate prepared with a large excess of iron. This coincidence suggests that the model proposed in this study to explain the structure of the iron:phytate may also be applicable to $\mathrm{CP}$ precipitates.

The PhyBi-1 to PhyBi-4-treated samples have a lower content of phosphorus (Table 2) than those treated with the Phy-1 to Phy-4 solutions. Additionally, the CP aggregates, previously observed on the Phy-2 to Phy-4-treated samples no longer are present after deacidification. This demonstrates that the application of $\mathrm{CC}$ deacidification removes all the $\mathrm{CP}$ aggregates, and approx. $30 \%$ of the CP that is evenly distributed in the paper. Nevertheless, the $\mathrm{CP}$ that remains in the paper is enough to inhibit iron and thus protect the paper. Finally, the calcium contents of the PhyBi-1 to PhyBi-4-treated samples can be accounted for by adding the contributions due to $\mathrm{CP}$ [using the previously mentioned stoichiometry $(\mathrm{Ca} / \mathrm{P}=0.6)]$ and $\mathrm{CC}$ with a calcium loading of approx. 30 micro Mol per gram of paper (similar to that measured on the Bi-treated samples).

\section{Evolution of $\mathrm{Fe}(\mathrm{II}) / \mathrm{Fe}(\mathrm{III})$ ratio}

In the XANES spectra it can be observed that all samples contain a large excess of Fe(III) (Fig. 1). However, small displacements of the absorption edge show that the proportion of $\mathrm{Fe}$ (II) varies from one sample to another. It is for instance smaller for Phy-1 samples than for W30 samples.

The $\mathrm{Fe}(\mathrm{II}) / \mathrm{Fe}(\mathrm{III})$ ratios were measured on three sets of samples prepared at different periods. These samples were therefore exposed to different post-treatment ageing (respectively 2 and 15 months of natural ageing and 70 days of artificial ageing). On these three sets of measurements, similar results were obtained, showing that the $\mathrm{Fe}(\mathrm{II}) / \mathrm{Fe}$ (III) ratio remains (at least at the precision level of our measurements) stable after a period of 2 months. Thus, average values are presented in Fig. 4.

Water (W30 and W60) removes $\mathrm{Fe}(\mathrm{II})$ and $\mathrm{Fe}(\mathrm{III})$ in similar proportions, and thus does not change the percentage of $\mathrm{Fe}(\mathrm{II})$ (approx. 15-20\%). In contrast, the phytate treatment changes the $\mathrm{Fe}(\mathrm{II}) / \mathrm{Fe}(\mathrm{III})$ ratio toward lower values. Several explanations can be put forward: first, $\mathrm{Fe}(\mathrm{II})$ is known to be more stable in acidic than in a neutral-alkaline environment. An oxidation of iron could thus be expected in deacidified samples. This effect is however not dominant, because the highest proportion of Fe(III) is found on the sample Phy-1 that is not deacidified. A more convincing explanation consists in considering that phytate can behave as a potent ferroxidase that greatly accelerates the oxidation of $\mathrm{Fe}(\mathrm{II})$, as pointed out by Graf et $a .^{48}$

\section{Interpretation of the BPT}

The BPT evaluates the presence of Fe(II) that is susceptible to migrate in the paper strip and is available to react with bathophenanthroline. In the case of a hard competition with other chelating compounds, such as carbonate, gallic acid or phytate, ${ }^{33}$ the strongly bound Fe(II) may not be detected by the BPT. Also the fact that no iron is available to react with

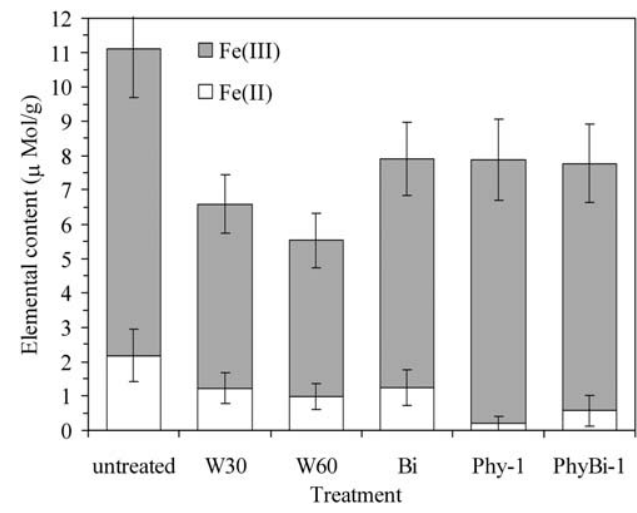

Fig. 4 Concentrations of $\mathrm{Fe}(\mathrm{II})$ and $\mathrm{Fe}(\mathrm{III})$ in the paper. 
Table 3 Results of the BPT (++: positive, dark red colour; +: slightly positive, light red colour, -: negative: no colour). Artificial ageing was performed for 19 days. "No" means that the tests were performed immediately after treatment, before the paper is dried

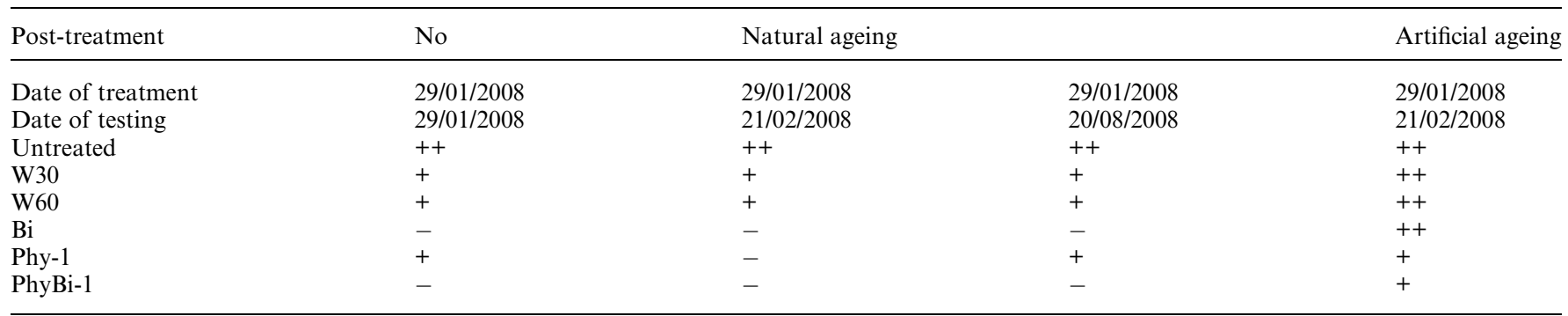

bathophenanthroline does not necessarily mean that it is totally inhibited.

The BPT applied on our laboratory samples gives a good illustration of these considerations (Table 3). The test was performed by placing a piece of dry BPT strip directly in contact with the wet samples in order to achieve the best sensitivity. It should first be pointed out that different results are obtained depending on whether the test is performed before or after drying: on Phy-1 samples, it is slightly positive immediately after treatment, and becomes negative after drying, meaning that (a) some oxidation of $\mathrm{Fe}$ (II) occurred and/or (b) the precipitation of iron and phytate is completed during the drying process.

Table 3 shows that BPT cannot be considered as a predictive tool for the assessment of the quality of a treatment: Bi, Phy-1 and PhyBi-1 samples are all BPT negative after drying, yet only PhyBi-1 samples are efficiently stabilized by the treatment. More generally, the $\mathrm{Fe}(\mathrm{II})$ availability toward bathophenanthroline increases with time, irrespective of the treatment efficacy and the type of ageing considered (artificial or natural). However, the fact that the BPT turns positive does not mean necessarily that the paper will degrade faster: on PhyBi-1 samples for instance, the BPT turns positive after approx. 1 month of artificial ageing; yet Fig. 2 shows that the mechanical properties of the sample remain stable even after this period.

The fact that the paper may contain some Fe(II) that is not available to react with bathophenanthroline is illustrated by the comparison of BPT results with XANES measurements. The Fe(II) and $\mathrm{Fe}$ (III) contents of the treated samples, as measured by means of XANES and ICP-AES (see Fig. 4), are relatively stable because similar values were obtained on the three sets of samples (after respectively 2 and 15 months of natural ageing, or 70 days of artificial ageing). In contrast, the BPT results depend largely on the sample ageing (see Table 3), showing that the speciation of Fe(II) is largely time dependent. In these conditions, the use of the BPT for the evaluation of the treatment efficacy appears hazardous.

Finally, the order of magnitude of the BPT sensitivity, as deduced from Fig. 4 and Table 3, is at least $1 \mu \mathrm{Mol} \mathrm{g}{ }^{-1}$ and is therefore largely inferior to the iron content of original manuscripts that usually ranges from $20 \mu \mathrm{Mol} \mathrm{g}^{-1}$ (ref. 49) to more than $200 \mu \mathrm{Mol} \mathrm{g}^{-1}$ (ref. 50). This confirms the high sensitivity of this test that is particularly appropriate for the detection of iron on original manuscripts and drawings.

\section{The requirement for a deacidification method}

The CP solutions, when used alone, are poorly efficient in delaying the paper alteration. In contrast, when combined with
CC deacidification, the global treatment becomes highly efficient. It first could be claimed that the $\mathrm{CP}$ solution prevents oxidative mechanisms, whereas the CC solution prevents acid hydrolysis. This argumentation should however be re-considered, as it was recently demonstrated ${ }^{11}$ that the cellulose depolymerisation induced by iron gall inks is mainly due to oxidative mechanisms provoked by surrounding oxygen, and largely enhanced by the presence of iron in the paper. Consequently, the fact that $\mathrm{CP}$ treatment, when performed alone (Phy-1 to Phy-4), remains inefficient in preventing cellulose degradation, means that phytate does not inhibit iron. Considering existing data, the ability of phytate to chelate iron is correlated to its capacity to block all iron coordination sites. This behaviour was unambiguously demonstrated in neutral to low alkaline conditions, ${ }^{26}$ but no experimental data were found at lower $\mathrm{pH}$ values. Phytate is usually considered to have a higher affinity with $\mathrm{Fe}(\mathrm{III})$ than with $\mathrm{Ca}(\mathrm{II})$, but the $\mathrm{pH}$ may have an impact on these affinities. Moreover, in acidic environment, protons are obviously competing with calcium and iron for phytate bounding. This competition is more favourable to iron and calcium when the $\mathrm{pH}$ is higher, because there are less protons available. We think that the iron which remains in the paper after CP treatment is only poorly bound to $\mathrm{CP}$, because most coordination sites are already occupied by protons or calcium. Iron is also not inhibited. When the treatment is followed by deacidification, the $\mathrm{pH}$ of the paper raises to approx. 8 during the drying process. As a result, approx. two of the phytate protonated sites become available for iron bounding. This might be enough to provoke its inhibition.

This scenario gives some elements to understand the poor efficiency of CP solutions when used alone. Further investigation remains necessary to determine if the CC solution is necessary as such, or if any deacidification treatment could be used with similar results.

\section{Conclusion}

This study confirms, in a systematic and documented way, the efficiency of the calcium phytate treatment for delaying iron gall ink damages. The $\mathrm{pH}$ of the phytate solution has no impact on the long term efficiency of the treatment, but the implementation of a calcium carbonate deacidification treatment after the use of calcium phytate solutions appears absolutely necessary to assure the efficacy of the whole process. A scenario is proposed to explain this point.

The bathophenanthroline paper test was additionally evaluated. It appeared poorly reliable to predict the long term 
efficiency of the treatment. It however remains a very sensitive tool for the identification of iron based inks as it was estimated that it can detect a quantity of iron that is of the order of $1 \mu \mathrm{Mol} \mathrm{g}{ }^{-1}$.

Side effects provoked by the treatment were also investigated. The precipitation of calcium phytate occurring in the treating solution over a $\mathrm{pH}$ value of 5 may induce the deposition of some calcium phytate aggregates on the surface of the paper. However, these aggregates remain a minor quantity compared to the total calcium phytate deposition and are removed during the second part of the treatment. These minor side effects consequently do not compromise the treatment efficiency.

Substantial chemical changes were observed on laboratory samples: sulphates are entirely lost during the treatment, whereas most iron remains. As for calcium phytate, it seems to be distributed homogeneously in the paper. None of these changes appears critical. This work will also be pursued on original samples, whose composition is more complex, in order to document in a more realistic way the side effects of this treatment.

\section{Acknowledgements}

This research was funded by SOLEIL (proposals 20060396 and 20080761) and was supported by the Interuniversity Attraction Poles Programme-Belgian Science Policy (IUAP VI/16). The text also presents results of GOA "XANES meets ELNES" (Research Fund University of Antwerp, Belgium) and from FWO (Brussels, Belgium) projects no. G.0704.08 and G.01769.09. We are thankful to the paper conservator students of the Institut National du Patrimoine who were involved in some of the sample preparations, and to Dr Dominique Thiaudière and Dr Solenn Reguer for their assistance and help during the experiments performed at SOLEIL beamline "DIFFABS".

\section{Notes and references}

1 A. E. Fazary, M. Taha and Y. H. Ju, J. Chem. Eng. Data, 2009, 54(1), 35-42.

2 C. Krekel, Diplomarbeit, Institut für Anorganishe Chemie, Georg August Göttingen University, 1990.

3 C. H. Wunderlich, Diplomarbeit, Fach Chemie an der Rheinishen Friedich-Whilhems, University of Bonn, 1990.

4 L. L. Lu, Y. H. Li and X. Y. Lu, Spectrochim. Acta, Part A, 2009, 74, 829-834.

5 A. Kongdee and T. Bechtold, Carbohydr. Polym., 2004, 56, 47-53.

6 H. Kipton, J. Powel and M. C. Taylor, Aust. J. Chem., 1982, 35, 739756.

7 G. Banik and H. Weber, Tintenfrassschäden und ihre Behandlung, Kohlhammer, Stuttgart, 1999.

8 Iron Gall Inks: on Manufacture, Characterisation, Degradation, and Stabilisation, ed. J. Kolar and M. Strlic, National and University Library, Ljubljana, 2006.

9 V. S. Selih, M. Strlic, J. Kolar and B. Pihlar, Polym. Degrad. Stab., 2007, 92, 1476-1481.

10 M. Strlic, J. Kolar and B. Pihlar, Polym. Degrad. Stab., 2001, 73, 535539.

11 V. Rouchon, M. Duranton, C. Burgaud, E. Pellizzi, B. Lavedrine, K. Janssens, W. De Nolf, G. Nuyts, F. Vanmeert and K. Hellemans, Anal. Chem., 2011, 83, 2589-2597.
12 V. Rouchon, B. Durocher, E. Pellizi and J. Stordiau-Pallot, Stud. Conserv., 2009, 54, 236-254.

13 B. Wagner and E. Bulska, Anal. Bioanal. Chem., 2003, 375, $1148-$ 1153.

14 M. Sala, J. Kolar, M. Strlic and M. Kocevar, Carbohydr. Res., 2006, 341, 897-902.

15 J. Kolar, M. Strlic, M. Budnar, J. Malesic, S. Selih and J. Simcic, Acta Chim. Slov., 2003, 50, 763-770.

16 G. Ceres, V. Conte, V. Mirruzzo, J. Kolar and M. Strlic, ChemSusChem, 2008, 1, 921-926.

17 J. Kolar, A. Mozir, A. Balazic, M. Strlic, G. Ceres, V. Conte, V. Mirruzzo, T. Steemers and G. De Bruin, Restaurator, 2008, 29, 184-198.

18 J. G. Neevel, Restaurator, 1995, 16, 143-160.

19 A. Zappala and C. de Stefani, Restaurator, 2005, 26, 36-43.

$20 \mathrm{~B}$. Reissland and S. de Groot, Proceedings of the 9th International Congress of IADA, Copenhagen, August 15-21, 1999, pp. 121129.

21 U. Henniges and A. Potthast, Restaurator, 2008, 29, 219-234.

22 J. G. Neevel, Proceedings of the Iron Gall Ink Meeting, Newcastle upon Tyne, 2000, pp. 125-131.

23 J. Kolar and M. Strlic, Proceedings of the Iron Gall Ink Meeting, Newcastle upon Tyne, 2000, pp. 135-139.

24 L. Botti, O. Mantovani and D. Ruggiero, Restaurator, 2005, 26, 44 62 .

25 J. Kolar, A. Mozir, M. Strlic, G. de Bruin, B. Pihlar and T. Steemers, e-Preserv. Sci., 2007, 4, 19-24.

26 E. Graf and J. W. Eaton, Free Radical Biol. Med., 1990, 8, 61-69.

27 E. Graf, Phytic Acid: Chemistry and Application, Pilatus Press, Minneapolis, USA, 1986.

28 E. Graf and J. R. Mahoney, J. Biol. Chem., 1984, 259, 36203624.

29 http://www.knaw.nl/ecpa/ink/CaPhytate.html, 1 November 2010.

30 B. Reissland, Restaurator, 1999, 20, 167-180.

31 Standard ISO 535: 1991 or TAPPI T441 om-90.

32 C. Remazeilles, V. Rouchon-Quillet, J. Bernard, T. Calligaro, J. C. Dran, L. Pichon, J. Salomon and M. Eveno, Restaurator, 2005, 26, 118-133.

33 C. Remazeilles, V. Quillet, T. Calligaro, J. C. Dran, L. Pichon and J. Salomon, Nucl. Instrum. Methods Phys. Res., Sect. B, 2001, 181, 681-687.

34 J. G. Neevel and B. Reissland, Papier Restaurierung, 2005, 6, 28.

35 J. G. Neevel, Restaurator, 2009, 30, 3-15.

36 V. Duplat, V. Rouchon, I. Desloges and M. C. Papillon, Journal of Paper Conservation, 2009, 3, 26-34.

37 Standard TAPPI T $231 \mathrm{~cm}-85$.

38 Standard ISO 6588-1:2005.

39 Standard NF T 12-025, March 1982.

40 M. Wilke, O. Hahn, A. B. Woodland and K. Rickers, J. Anal. At. Spectrom., 2009, 24, 1364-1372.

41 A. Voegelin, R. Kaegi, J. Frommer, D. Vantelon and S. J. Hug, Geochim. Cosmochim. Acta, 2010, 74, 164-186.

42 G. Mali, M. Sala, I. Arcon, V. Kaucic and J. Kolar, J. Phys. Chem. B, 2006, 110(46), 23060-23067.

43 C. Burgaud, V. Rouchon, P. Refait and A. Wattiaux, Appl. Phys. A: Mater. Sci. Process., 2008, 92, 257-262.

44 K. Subba Rao and B. S. Narasinga Rao, Nutr. Rep. Int., 1983, 28(4), $771-782$.

45 Standard ISO 10716:1994.

46 E. Graf, J. Agric. Food Chem., 1983, 31(4), 851-855.

47 L. Heighton, W. F. Schmidt and R. L. Siefert, J. Agric. Food Chem., 2008, 56, 9543-9547.

48 E. Graf, K. L. Empson and J. W. Eaton, J. Biol. Chem., 1987, 262(4), $11647-11650$.

49 C. Remazeilles, V. Rouchon-Quillet, J. Bernard, T. Calligaro, J. C. Dran, L. Pichon, J. Salomon and M. Eveno, Restaurator, 2005, 26, 118-133.

50 C. Remazeilles, V. Quillet, T. Calligaro, J. C. Dran, L. Pichon and J. Salomon, Nucl. Instrum. Methods Phys. Res., Sect. B, 2001, 181, 681-687. 